\title{
POLITIK EKONOMI ISLAM KOMPARASI HUKUM DAN NILAI SISTEM EKONOMI DUNIA
}

\section{Sumar'in}

Fakultas Syariah dan Ekonomi Islam Institut Agama Islam (IAI) Sultan M.Syafiuddin

Email : sumarinasmawi @yahoo.co.id.

\begin{abstract}
The Islamic Economic Doctrine is a comparative study that looks at the fundamental principles of Islamic economics, and compares them with the economic and philosophical foundations of capitalism and Marxism. It identifies through a review of theoretical economics the structural problems that lie in the current economic order. Poverty and Inequality have increased in last two decades and the millennium development goals are still far from achieved. The research identifies that lack of an ethical foundation, unbridled pursuit of self interest in production as well as in consumption, interest based financial ad monetary system are the major problematic issues in Capitalism against which mixed economy has also shown limited effectiveness. Socialism promises to create heaven on earth, but takes fundamental human rights and profit motive away and in the extreme case give way for an autocratic or totalitarian regime. Islamic economic system in its true sense is not present in any country. It is a blend of natural features present in Capitalism i.e. right to private property, private pursuit of economic interest, use of market forces etc. used along with some distinct features derived through Islamic economic teachings i.e. interest free economy, moral check on unbridled self-pursuit and provision of socio-economic justice to achieve the goals of Socialism as far as is naturally possible without denying individual freedom and profit motive.
\end{abstract}

Keywords: Law, Value, and Economic System

\begin{abstract}
Abstrak
Doktrin Ekonomi Islam adalah studi perbandingan yang melihat prinsip-prinsip dasar ekonomi Islam, dan membandingkannya dengan fondasi ekonomi dan filosofis kapitalisme dan Marxisme. Ini mengidentifikasi melalui tinjauan ekonomi teoritis masalah struktural yang terletak pada tatanan ekonomi saat ini. Kemiskinan dan Ketimpangan telah meningkat dalam dua dekade terakhir dan tujuan pembangunan milenium masih jauh dari tercapai. Penelitian ini mengidentifikasi bahwa kurangnya landasan etis, pengejaran kepentingan pribadi dalam produksi dan konsumsi, sistem keuangan dan moneter berbasis bunga adalah masalah besar dalam Kapitalisme di mana ekonomi campuran juga menunjukkan efektivitas yang terbatas. Sosialisme berjanji untuk menciptakan surga di bumi, tetapi menghilangkan hak asasi manusia dan motif keuntungan dan dalam kasus ekstrem memberi jalan bagi rezim otokratis atau totaliter. Sistem ekonomi Islam dalam arti sebenarnya tidak ada di negara mana pun. Ini adalah perpaduan fitur alami yang ada dalam Kapitalisme yaitu hak atas kepemilikan pribadi, pengejaran pribadi atas kepentingan ekonomi, penggunaan kekuatan pasar, dll. Digunakan bersama dengan beberapa fitur berbeda yang diperoleh melalui ajaran ekonomi Islam yaitu ekonomi bebas bunga, pemeriksaan moral terhadap diri sendiri yang tak terkendali. mengejar dan menyediakan keadilan sosialekonomi untuk mencapai tujuan Sosialisme sejauh mungkin secara alami tanpa mengingkari kebebasan individu dan motif keuntungan.
\end{abstract}

Kata Kunci : Hukum, Nilai dan sistem Ekonomi 


\section{PENDAHULUAN}

Semenjak manusia lahir di bumi, ia akan senantiasa berusaha untuk menjaga eksistensi dan fungsinya dimuka bumi sebagai seorang khalifah. Untuk mewujud- kan hal tersebut manusia melakukan kom- petisi dengan lingkungannya baik dengan alam, tumbuhan, binatang maupun dengan manusia itu sendiri. Kompetisi yang terjadi tersebut akan sangat dipengaruhi oleh sumber daya (resources) sebagai hukum positif dan nilai-nilai ketuhanan sebagai hukum normatife. Dengan kata lain siapa yang paling mampu mengoptimalkan sum- ber daya tersebut yang diikuti nilai-nilai keagamaan, maka ia akan menjadi pemenang. Dalam hal pemenuhan kebutuhan ekonomi, menjadi hal yang lumrah seorang manusia dituntut untuk mampu mengoptimalkan fungsi-fungsi ekonomi dalam dirinya yakni fungsi produksi, fungsi distribusi dan akhirnya melakukan konsumsi dengan tetap memegang nilai-nilai dan etika kemanusiaan. ${ }^{1}$

Semakin bertambahnya kuantitas manusia dimuka bumi secara otomatis akan semakin besarnya kompetisi yang terjadi. Hal ini menuntut pemikiran yang keras (Ijtidah) untuk menghasilkan sistem eko- nomi yang paling tepat dan sesuai, dalam rangka mempertahankan eksistensi individu manusia masing-masing, tanpa harus men- dzolimi dan membunuh karakter dari masya- rakat lain. Dengan harapan tercipta sebuah tatanan masyarakat yang seimbang, adil dan kesejahteraan secara merata.

Dalam peradaban pemikiran manusia, pernah tercatat beberapa hegomoni besar yang mendominasi pemikiran ekonomi manusia. Yakni pemikiran ekonomi Merkan- tilisme, ekonomi liberalisme, Kapitalis dan ekonomi Sosialis yang di kumandangkan oleh Karl Marx serta ekonomi alternatife yang selanjutnya disebut sebagai ekonomi Islam. Upaya untuk menterjemahkan pemi- kiran ekonomi tersebut ketataran praktis, setiap pemikiran tersebut memiliki formulasi dalam upaya untuk meraih tujuan ekonomi sesuai dengan filosofi yang di anut dalam sistem ekonomi.

\section{PEMBAHASAN}

\section{Teori Politik Ekonomi Islam}

Politik ekonomi adalah tujuan yang ingin dicapai oleh hukum-hukum yang dipergunakan untuk memecahkan mekanisme yang mengatur urusan manusia. Sedangkan politik ekonomi Islam adalah jaminan tercapainya semua kebutuhan prime (basic needs) tiap orang secara menyeluruh,

\footnotetext{
${ }^{1}$ Said Saad Morthon Teri, Akhmad Ikhrom, Ekonomi Islam di Tengah Krisis Ekonomi Global, (Jakarta : Zikrul Kalam, 2004),Hal. ix
} 
berikut kemungkinan tiap orang untuk memenuhi kebutuhan sekunder dan tersiernya sesuai dengan kesanggupannya, sebagai individu yang hidup dalam sebuah masyarakat yang memiliki gaya hidup tertentu. $^{2}$

Politik ekonomi Islam merupakan sebuah rangkaian formulasi yang dijadikan pedoman dalam meraih kemakmuran dan kesejahteraan ekonomi pada setiap individu dengan menjadikan nilai- nilai agama sebagai hal yang tetap harus dikedepankan. Adapun rangkaian formulasi tersebut adalah hukum-hukum agama yang tertuang dalam Al-Qur"an dan Hadist. Sebagai ilustrasi, dalam politik ekonomi Islam diatur dan dijelaskan bagaimana untuk memenuhi kebutuhan primer hidup setiap manusia, sesuai dengan budaya dan pola yang terjadi pada masyarakat tersebut seperti kebutuhan akan sandang, pangan dan papan. Ketika seseorang tidak mampu untuk meraih kebutuhan primer tersebut Islam mewajibkan kepada anak dan ahli warisnya untuk memenuhi nafkah dan kebutuhannya, namun ketika tidak ditemukannya anak dan ahli waris yang mampu maka orang tersebut menjadi tanggungan baitul maal atau negara. Dalam Politik ekonomi Islam, memberikan kewajiban pada setiap warga Negara untuk melakukan usaha dalam upaya memenuhi kebutuhan hidupnya dengan tetap memperhatikan nilai-nilai agama. Namun ketika seseorang tidak mampu untuk memenuhinya maka menjadi kewajiban bagi orang terdekat atau negara sebagai salah satu pelaku dan pengawas ekonomi. Oleh karena itu politik ekonomi Islam berdiri di atas suatu konsep, yaitu men- jalankan aktivitas ekonomi berdasar-kan hukum Islam yang diterapkan oleh tiap orang dengan dorongan ketakwaan pada Allah Swt. serta dilaksanakan oleh Negara. Dipergunakan untuk memecahkan mekanisme yang mengatur urusan manusia. Sedangkan politik ekonomi Islam adalah jaminan melalui pembianaan undangan hukum syara. ${ }^{3}$

\section{Mazhab Ekonomi Dunia}

Tingginya kebutuhan manusia menuntut adanya sebuah perjuangan untuk meraih kebutuhan. Dalam konsep Islam, kebutuhan manusia akan senantiasa berbanding sejajar dengan alat pemuas kebutuhan tersebut. Dan bahkan sesungguhnya alam raya ini pasti mampu untuk memuaskan kebutuhan manusia, sehingga tidak akan ada kebutuhan manusia yang tidak terpenuhi, dalam hal ini kepuasan pasti akan mampu untuk diraih Namun keserakahan dan ketamakan adalah penyakit ekonomi yang sangat rentan dalam meraih kepuasan tersebut. Untuk itu nilai agama

\footnotetext{
${ }^{2}$ Nabhani An-Taqyuddin, Terj. Maghfur Wachid, Membangun Sistem Ekonomi Alternatif Perspektif Islam, (Surabaya: Risalah Gusti, 1996), Hal. 52

${ }^{3}$ Nabhani An-Taqyuddin, Terj. Maghfur Wachid, Ibid. Hal. 61
} 
menjadi bagian terpenting dalam mengawal tingkat kepuasan. Dalam rangka pengelolaan alam untuk meraih kebutuhan tersebut diperlukan sebuah pemikiran yang terintegrasikan dalam hal. Yang nantinya menghasilkan sebuah penemuan-penemuan materi dalam pengembangan peradaban. Kekayaan pemikiran ini sangat bernilai harganya yang tidak terbayar oleh nilai apapun, sehingga menjadi pantas pemikiran tersebut untuk dilestarikan dan dikembangkan menjadi sebuah identitas dan karakteristik suatu bangsa.

Dengan sebuah pemikiran yang cemerlang, sehancur apapun sebuah kebudayaan akan mampu untuk dibangun dan dipulihkan ulang. Karena pemikiran akan menghasilkan karya dan materi-materi baru yang lebih hebat dari sebelumnya. Untuk itu orientasi pengembangan dan pelestarian sepantasnya lebih difokuskan pada pengembangan dan pelestarian pemikiran bukan pada aspek materialnya. Dengan pemikiran yang tinggi aspek material akan dapat dikembangkan. Namun tidak untuk sebaliknya, bahkan ketika sebuah bangsa hanya mengandalkan aspek material dan meninggalkan aspek pemikiran maka akan dengan mudah untuk dihancurkan. Yang dimaksud pemikiran disini adalah adanya aktivitas berpikir pada diri umat manusia tentang realitas kehidupan yang mereka hadapi. Dimana mereka masing-masing secara keseluruhan senantiasa mempergunakan informasi yang mereka miliki ketika mengindra berbagai fakta ataupun fenomena untuk menentukan hakikat fakta atau fenomena tersebut. ${ }^{4}$

Fenomena yang terjadi pada umat Islam saat ini dihadapkan pada kehilangan pemikiran (Ijtihad) untuk menggali khazanah dan keagungan ajarannya. Kecenderungan terbesar yang terjadi pada mereka hanyalah tereuforior oleh kehebatan sejarah serta hanya memanfaatkan nilai material dari hasil ijtihad dari pendahulunya. Ketakutan dan ketidak mampuan untuk melakukan pemikiran membuat masyarakat muslim dihadapkan pada kondisi stagnan atau bahkan semakin menurun. Tak heran dalam segala sendi kehidupan membuat kaum yang di sebut sebagai kaum kapitalis, lebih menghegemoni peradaban dunia pada masa sekarang.

Sebelumnya kita mengenal bagaimana peranan kaum Marxisme (red: Sosialis) pernah mendominasi, juga jauh sebelumnya Islam merupakan pemain dalam hegemoni peradaban yang pernah memegang peradaban tertinggi. Penulis melihat saat ini adanya sebuah trend pasar yang coba dibangun oleh kaum cendekiawan muslim untuk mengubah kiblat pasar dari kapitalis menuju ekonomi yang berprinsip-kan Islam, namun ketika bangunan pemikirannya tidak matang dan

\footnotetext{
${ }^{4}$ Nabhani An-Taqyuddin, Terj. Maghfur Wachid, Ibid Hal. 2
} 
kokoh maka hal tersebut merupakan sebuah perlawanan yang bersifat semu. Oleh itu dibutuhkan sebuah pemikiran secar berjama ${ }^{e e}$ ah dari cendekiawan muslim dengan penuh sinergisitas.

Pada tataran normative kita melihat bagaimana keunggulan ekonomi Islam. Sebagai sebuah konsep ekonomi, Islam memiliki aturan yang jelas yakni al-qure an dan Hadist. Untuk itu perlunya interpretasi dan pentafsiran nilai-nilai agama agar tidak selamanya melangit. Berbeda dengan beberapa sistem ekonomi lainnya, hanya menjadikan nilai-nilai akal sebagai bagian tertinggi dalam menyusun kerangka ekonomi. Sehingga di tataran praktis seringkali ajaranajaran yang dikeluarkan akan bertentangan dengan nilai fitrah dan kemanusiaan.

Aliran Merkantilisme Aliran perekonomian dalam madzhab ini sering juga disebut sebagai madzhab pedagang dimana sistem perekonomian berpusat pada kegiatan perdagangan dilintas regional. Orientasi yang timbul dalam perdagangan ini adalah untuk memperoleh emas dan perak sebanyak-banyaknya dengan harapan menjadikan negara lebih kuat dan mewujudkan keseimbangan pada neraca perdagangan (trade balance). Aliran dengan sistem perekonomian ini berkembang pada abad ke 15 sampai abad ke 18. Kegiatan yang menjadi identitas dalam perekonomian ini adalah kewajiban pajak, bea cukai atas kegiatan ekspor impor dan pemberian subsidi atas kegiatan produksi sebuah usaha serta besarnya intervensi pemerintah dalam kegiatan ekonomi terutama dalam hal penentuan upah dan harga serta pendirian berbagai macam jenis industri. Ada beberapa faktor yang mendukung muncul dan lahirnya madzhab ini meliputi $:^{5}$

a. Runtuhnya sistem feodalis yang diakibatkan oleh perlawanan kaum buruh untuk menuntuk peningkatan taraf hidup yang cenderung memilih berdagang.

b. Kecenderungan untuk menciptakan keseimbangan ekonomi pada neraca perdagangan dalam mendapatkan emas dan perak.

c. Penemuan daerah baru dan politik imprealisme.

Namun disisi lain sistem ini juga menimbulkan kelemahan yang mengakibatkan munculnya madzab baru. Kelemahan tersebut meliputi : ${ }^{6}$

a. Madzhab ini mendewakan urgensitas perdagangan regional yang mengakibatkan meminimalisir biaya produksi dengan segala cara.

b. Kebijakan perekonomian terfokus pada perkembangan industry.

c. Nilai emas dan perak tidaklah selamanya stabil.

\footnotetext{
${ }^{5}$ Said Saad Morthon Terj. Akhmad Ikhrom, Ibid Hal. 6

${ }^{6}$ Said Saad Morthon Terj. Akhmad Ikhrom, Ibid Hal. 7
} 
d. Politik imprealisme mendorong kedzoliman dan eksploitasi.

\section{Aliran Liberalisme}

Akibat besarnya perlawanan terhadap sistem ekonomi Merkantilisme yang berbasis perdagangan antar regional, maka muncullah sebuah faham ekonomi yang mengagungkan perdagangan antar domestik dan menyebabkan hancurkan sistem ekonomi perdagangan. Sistem ekonomi ini selanjutnya di kenal dengan istilah sistem kebebasan ekonomi. Pada dasarnya sistem ini telah dirintis oleh pemikir terdahulu pada abad ke-18 oleh Fransco, Tourju dan Mirabu. Prinsip dasar ekonomi ini adalah:

a. Kehidupan ekonomi bersandar atas hukum alam, sehingga pemerintah hanya menjaga stabilitas ekonomi dan kebijakan luar negeri.

b. Independensi ilmu ekonomi dari semua unsur agama, etika dan ilmu sosial.

c. Mengakui kepemilikan individu.

d. Kemaslahatan individu merupakan motivator untuk bekerja dan beramal.

e. Adanya pemahaman kemaslahatan individu adalah segalanya.

Aliran ini merupakan rintisan dari pemikiran Adam Smith yang selanjutnya dikenal sebagai aliran Konvensional (Classic mainstream). Adapun aplikasi pemikiran Adam Smith yang ditulis dalam "The Wealth of Nation" meliputi:

a. Bekerja merupakan sumber kesejahteraan, bukan pertanian atau perdagangan.

b. Profesionalisme dalam bekerja mampu meningkatkan hasil produksi.

c. Kebebasan dalam berkompetisi

\section{Aliran Kapitalisme}

Aplikasi dari konsep aliran kebebasan ekonomi memberikan stimulasi bagi timbulnya sektor industri, perdagangan dan modal di negara-negara Eropa. Dengan menjamurnya industri dan perdagangan, income dan modal yang dimiliki oleh individu semakin berkembang sehingga melahirkan pemiliki modal dan sistem perekonomian Capitalisme. Pada dasarnya sistem ekonomi ini merupakan perluasan dari sistem ekonomi liberal dimana kompetisi dan persaingan bebas menjadi bagian terpenting Dari aplikasi sistem kapitalime ini timbulah kesenjangan sosial, kesejahteraan masyarakat menjadi sulit untuk direalisasikan. Akibatnya terjadi inflasi besarbesaran di Jerman dan Negara-negara Eropa lainnya (1923, serta deficit yang diderita Negara Amerika (1929-1933), akibatnya terhenti produksi dan systemic risk dalam dunia perbankan. Hal tersebut diikuti adanya PHK secara besar-besaran. 


\section{Aliran Sosialisme}

Aliran sosialisme ini berawal dari faham sosialis yang di prakarsai oleh Karl Marx pada abad ke-18. Aliran ini sebagai perlawanan dari faham kapitalisme dimana dalam konsep ini tidak diakuinya kepemilikan modal pribadi. Hal ini menimbulkan hilangnya semangat untuk berproduksi, karena modal hanya boleh dimiliki untuk kegunaan bersama dimasyarakat. ${ }^{7}$ Pada abad ke-20 sistem sosialisme ini sudah menyebar di sebagian besar wilayah Eropa Timur. Keberlangsungan sistem ini ditandai dengan adanya revolusi Rusia pada tahun 1917 lewat sebuah gerakan anti Kapitalisme yang terinspirasi oleh konsep sosialisme.

\section{Aliran Ekonomi Islam}

Sistem ekonomi Islam berbeda dari Kapitalisme, Sosialisme, maupun Negara Kesejahteraan (Welfare State). Berbeda dari Kapitalisme karena Islam menentang eksploitasi oleh pemilik modal terhadap buruh yang miskin, dan melarang penumpukan kekayaan. "Kecelakaanlah bagi setiap ... yang mengumpulkan harta dan menghitunghitung”'. Orang miskin dalam Islam tidak dihujat sebagai kelompok yang malas dan yang tidak suka menabung atau berinvestasi. Ajaran Islam yang paling nyata menjunjung tinggi upaya pemerataan untuk mewujudkan keadilan sosial, "jangan sampai kekayaan hanya beredar dikalangan orang-orang kaya saja diantara kamu". ${ }^{8}$

Disejajarkan dengan Sosialisme, Islam berbeda dalam hal kekuasaan negara, yang dalam Sosialisme sangat kuat dan menentukan. Kebebasan perorangan yang dinilai tinggi dalam Islam jelas bertentangan dengan ajaran Sosialisme. Akhirnya ajaran Ekonomi Kesejahteraan (Welfare State) yang berada di tengah-tengah antara Kapitalisme dan Sosialisme memang lebih dekat ke ajaran Islam. Bedanya hanyalah bahwa dalam Islam etika benar-benar dijadikan pedoman perilaku ekonomi sedangkan dalam Welfare State tidak demikian, karena etika Welfare State adalah sekuler yang tidak mengarahkan pada "integrasi vertikal" antara aspirasi materi dan spiritual. Demikian dapat disimpulkan bahwa dalam Islam pemenuhan kebutuhan materiil dan spiritual benar-benar dijaga keseimbangannya, dan pengaturaan oleh negara, meskipun ada, tidak akan bersifat otoriter. State intervention, directed primarily at reconciling the possible social conflict between man"s ethical and economic behaviors cannot lead the society onto "road to serfdom" but will guide it gently along the road to human freedom and dignity (Naqvi,1951.h81). ${ }^{9}$ Dalam Ekonomi Islam

\footnotetext{
${ }^{7}$ Ibrahim Lubis, Ekonomi Islam Suatu Pengantar 2 (Jakarta: Kalam Mulia, 1995), Hal. 313

${ }^{8}$ Al-Qur'an, surah Al-Muzamil; 7

${ }^{9}$ Nagvi, Syed Nawab Haider, Ethics and Economics, An Islamic Synthesis, The Islamic Foundation, London, 1981.
} 
lebih mementingkan aspek nilai, DR. Said Sa ad Morton mengatakan bahwa dalam ekonomi Islam, selain sistem bagi hasil, ada empat karakteristik dasar yang membedakannya dengan ekonomi Kontemporer meliputi: ${ }^{10}$

Pertama, dialektika nilai-nilai spritualisme dan materialisme. Sistem ekonomi kontemporer hanya konsen terhadap niali yang dapat meningkatkan utility suatu barang atau terfokus pada nilainilai material. Sistem ini tidak pernah menyentuh nilai-nilai spritual dan etika kehidupan masyarakat, sehingga menciptakan individuindividu yang penuh dengan nilai-nilai individualisme, egoisme dan materialisme. Sedangkan dalam konsep ekonomi Islam terdapat dialektika antara nilai-nilai spritualisme dan materialisme. Hal ini menunjukkan sebuah konsep ekonomi yang menekankan nilai-nilai kebersamaan dan kasih sayang diantara sesama individu masyarakat.

Kedua, kebebasan berekonomi. Sistem ekonomi Islam tetap membenarkan kepemilikan individu dan kebebasan dalam bertransaksi sepanjang dalam koridor syariah. Juga memberikan hak dan kewajiban bagi setiap individu masyarakat dalam menciptakan keseimbangan hidup bermasyarakat, baik dalam bentuk produksi maupun konsumsi. Kebebasan ini akan mendorong masyarakat bekerja dan berproduksi demi tercapainya kemaslahana hidup masyarakat.

Ketiga, dualisme kepemilikan. Hakikat pemilik alam semesta beserta isinya hanyalah Allah. Manusia hanya sebagai wakil allah dalam memakmurkan dan mensejahterakan bumi. Kepemilikan yang dimiliki oleh manusia merupakan derivasi atas kepemilikan Allah yang hakiki (Istikhlaf) untuk itu setiap kebijakan ekonomi manusia harus senantiasa berlandaskan atas dasar kemakmuran bersama. Walaupun demikian manusia tetap diberikan kebebasan untuk mengelola dan memanfaatkan harta benda sesuai dengan norma dan nilai-nilai agama.

Keempat, menjaga kemaslahatan individu dan masyarakat. Konsep kehidupan ekonomi yang terdapat dalam Islam, senantiasa menjaga kemaslahatan bagi individu dan masyarakat. Kedua kemaslahatan tersebut tidak boleh didikotomi antara yang satu dengan yang lainnya. Dalam arti, kemaslahatan individu tidak boleh dikorbankan untuk kemaslahatan bersama atau demikian pula sebaliknya. Sehingga konsep distribusi harta sangat jelas diatur dalam Islam sebagai upaya untuk menjaga kemaslahatan bersama tanpa mendzolimi satu pihak yang terkait dalam kehidupan ekonomi.

Selanjutnya Adiwarman Karim menyatakan bahwa Konsep Dasar Ekonomi Islam dibangun atas filosofi yang jelas dan sangat kuat dengan nilai-nilai spritual dan nilai material.

\footnotetext{
${ }^{10}$ Said Saad Morthon Terj. Akhmad Ikhrom, Ibid Hal. 31
} 
Bangunan Ekonomi Islam didasarkan atas lima nilai universal, yakni Tauhid (Keimanan), „Adl (keadilan), Nubuwwah (kenabian) Khilafah (pemerintahan) dan Ma ${ }^{e e}$ ad (Hasil). Ini merupakan pondasi awal dari konsep ekonomi Islam, sehingga dalam penterjemahannya dilapangan lima prinsip dasar yang merupakan teori dan filosofi awal, harus mampu diterjemahkan dalam prinsip derivatif yang merupakan cikal bakal ekonomi Islam yang terdiri atas Multiple Ownership, Freedom to act dan Sosial Justice. ${ }^{11}$

Di atas nilai dan prinsip yang menaungi hal tersebut akan menimbulkan sebuah kemuliaan dan keluhuran Akhlak yang merupakan puncak sebuah sistem prilaku ekonomi, karena itulah yang menjadi tujuan Islam dan dakwah para nabi, menyempurnakan Akhlak manusia. Akhlak ini menjadi panduan para pelaku ekonomi dalam melakukan aktivatas dan bertransaksi dalam dunia ekonomi. Ketika akhlak dijadikan pedoman dalam kegiatan ekonomi dan bisnis, maka akan melahirkan sebuah etika yang luhur dan mulia dalam berbisnis menurut ajaran Islam yang bersumber langsung dari Al Quree an dan Hadist Nabi. Misalnya karena adanya larangan riba, maka variabel bunga yang menjadi sistem imbalan terhadap modal tidak akan diterapkan dalam praktek ekonomi Islam. Sebagai solusi Islam menerapkan sistem bagi hasil. Keluhuran Akhlak akan menciptakan semangat saling percaya, kejujuran, dan keadilan. Hal ini menjadi bagian dalam kehidupan ekonomi masyarakat.

\section{PENUTUP}

Politik ekonomi maka akan dihadapkan dengan sebuah konsep yang menjadi dasar dalam menempuh kesejahteraan bagi manusia. Oleh itu ketika berbicara tentang politik ekonomi Islam, maka kita juga akan dihadapkan dengan berbagai formulasi yang dijadikan acuan dalam teoritis ekonomi Islam untuk mensejahterakan manusia. Ciri dan identitas ini merupakan hasil dari sebuah proses ijtihad yang diharapkan mampu diaplikasikan dalam membuah dan merumuskan kebijakan ekonomi untuk kemaslahatan bersama. Namun perlu dicatat bahwa konsepsi dan kebijakan yang dikeluarkan oleh negaranegara yang mengaku bermadzhab kapitalisme dan sosialisme seringkali melakukan revolusi terhadap konsep ideal dari madzhab tersebut. sebagai contoh negara Cina yang mengaku sosialisme dalam aplikasinya mereka lebih bebas lagi dari negara kapitalisme atau liberalism. Demikian-pula halnya dengan negara-negara kapitalisme seperti Amerika Serikat dalam kebijakan ekonominya lebih sosialis bila dibanding negara Sosialis lainnya. Revolusi dan

\footnotetext{
${ }^{11}$ Adiwarman Karim, Ekonomi Mikro Islam (Jakarta: IIIT Indonesia, 2003), Hal. 48
} 
perubahan konsep dari makna awal ini sebagai upaya politik ekonomi yang dilakukan oleh sebuah negara untuk mengatasi permasalahan dalam perekonomian negara. Karena ketika mereka kaku terhadap konsep ideal sebuah madzhab ekonomi akan sangat sulit untuk mampu bertahan dalam menghadapi serangan dan gempuran dari politik ekonomi negara luar.

\section{DAFTAR PUSTAKA}

Abdul, Abdullah Husain at-Tariqi, Terj. M. Irfan Sofwani, Ekonomi Islam, Prinsip, Dasar dan Tujuan, Yogyakarta: Magistra Insani Press, 2004

Azwar Karim Adiwarman, Bank Islam Analisis Fiqh dan Keuangan, Jakarta: Raja Grafindo Persada, edisi ke-3 2007

Lubis Ibarahim, Ekonomi Islam Suatu Pengantar, Jild 2. Jakarta: Kalam Mulia, 1995.

Nabhani An-Taqyuddin, Terj. Maghfur Wachid, Membangun Sistem Ekonomi Alternatif Perspektif Islam, Surabaya: Risalah Gusti, 1996

Saad Morthon Said, Terj. Ahmad ikhrom, Ekonomi Islam Di Tengah Krisis Ekonomi Global, Jakarta: Dzikrul Hakim, 2004 